\title{
CONSUMO SIMBÓLICO DA ESFERA PRODUTIVA DAS MERCADORIAS: Significações de tradição, de memória e de história social ${ }^{1}$
}

\author{
Vander Casaqui $^{2}$
}

\begin{abstract}
Resumo: $O$ artigo trata das estratégias da publicidade contemporânea nas representações do mundo do trabalho e da esfera produtiva das mercadorias, como elementos de construção do universo simbólico das marcas. A partir da análise de três comerciais, das marcas Bauducco, Mitsubishi e Johnnie Walker, veiculados recentemente na televisão brasileira, refletimos sobre os processos de mitificação, os apagamentos, as ressemantizações de signos relacionados à produção para compor a visibilidade do trabalho pela lógica do consumo. A metodologia de análise do ethos discursivo organiza a leitura dos filmes publicitários que compõem o estudo.
\end{abstract}

Palavras-Chave: Publicidade. Consumo. Marcas.

\begin{abstract}
This article discusses the contemporary advertising strategies of representation work's world and productive sphere of goods, as elements of construction in the symbolic universe of brands. Using the analyses of three spots recently showed in Brazilian Television of brands Bauducco, Mitsubishi and Johnnie Walker, we intend to think over the mythification process, the forgetfulness, the re-semantization of signs related to the production to compound the work's visibility trough consumption logics. The discursive ethos' analyses methodology organizes the interpretation of advertisement films that are part of this study.
\end{abstract}

Key-words: Advertising. Consumption. Brands.

\section{Introdução}

A publicidade contemporânea exerce o papel de mediadora simbólica das relações entre produção e consumo. Como camada estética da mercadoria, de acordo com o conceito de Haug (1997), a linguagem publicitária reveste os processos produtivos e o mundo do trabalho do anunciante através de leituras lúdicas, mágicas, espetaculares. Analisamos a forma como a publicidade faz essa tradução da esfera de produção das mercadorias, utilizando como recurso os significados da memória, de

\footnotetext{
${ }^{1}$ Primeira versão do texto foi apresentada no VIII Congresso Lusocom, em Lisboa, Universidade Lusófona, 2009.

2 Doutor em Ciências da Comunicação pela ECA/USP; Docente do Programa de Mestrado em Comunicação e Práticas de Consumo - Escola Superior de Propaganda e Marketing - SP.

E-mail: vcasaqui@espm.br.
} 
história e de trabalho artesanal, para produzir o sentido idealizado das marcas. Essa leitura publicitária se apresenta como óculos sociais (Blikstein, 1985) a partir dos quais os processos internos que resultam na mercadoria são percebidos como harmônicos em relação ao universo simbólico das marcas.

Antes de abordarmos a publicidade audiovisual que traduz a esfera produtiva das mercadorias, contextualizamos a questão do consumo contemporâneo e do mundo do trabalho, uma vez que esse cenário sociocultural é determinante na forma e nas estratégias da linguagem publicitária - dessa maneira, consideramos a publicidade como uma das principais “teias de significados” (Geertz, 1978) da sociedade em que vivemos, e que não pode ser compreendida sem que se recorra ao universo mais amplo do qual é parte mais visível.

\section{Produção, consumo e comunicação - intersecções}

O mundo do trabalho no contexto contemporâneo sofre inúmeras transformações, influenciado pelas condições tecnológicas e pela ascensão do setor de serviços, que se coloca ao centro da sociedade de consumo; o sentido da imaterialidade reveste a atividade laboral humana em todas as suas esferas. Nesse quadro, o setor fabril e a prestação de serviços se aproximam. De acordo com Hardt e Negri (2006: 313), o trabalho informatizado impacta na produção de forma marcante, gerando uma real homogeneização de seus processos. A heterogeneidade do trabalho, que dispunha de ferramentas específicas para cada atividade, e um papel determinante do homem como produtor, passa agora pela "ferramenta universal”, o computador, pelo qual toda atividade deve transitar. As tecnologias da comunicação e a flexibilização da produção tornam a influência dos gostos do consumidor mais presentes no processo de desenvolvimento das mercadorias. Nesse sentido, caracteriza-se uma ampliação do afastamento entre produtor e produto, tal qual já apontava Marx a partir do conceito de trabalho estranhado (Marx, 2004); o trabalho fabril, sob esse aspecto, tende a ser mais abstrato do que concreto. O conceito de trabalho imaterial, que tem uma face marcada pela mediação do computador, também define as atividades identificadas pelo caráter analítico e simbólico; tarefas como planejamento, criação, pesquisa incorporam a subjetividade humana à estrutura corporativa de maneira cada vez mais intensiva. Outro aspecto imaterial é determinado pelo “trabalho afetivo” (Hardt e Negri, 2006: 313-4), 
predominante no setor de serviços, onde ação instrumental e ação comunicativa se imbricam, para resultar na produção de afetos e subjetividade, na relação direta com o público. Para os autores, o trabalho imaterial e afetivo compreende a cooperação e a interação sociais, de uma forma não imposta de fora para dentro, em coexistência com as imposições da cultura corporativa; o indivíduo possui um campo de manifestação espontânea com seus pares e no contato com os consumidores, dada essa condição de entrelaçamento entre produção, comunicação e afetividade características do trabalho como mediação fundamental do ser humano.

Se a condição humana se impõe no mundo do trabalho, como lugar de identidade e mediação, não se pode deixar de destacar os impactos do espírito do capitalismo contemporâneo, em que os movimentos globalizados do capital tornam a compressão do espaço e do tempo determinantes na predominância da efemeridade e descartabilidade, tanto no âmbito da produção quanto do consumo (Harvey, 2001: 2589). A obsolescência se generaliza por toda a sociedade: valores, modas, técnicas, gostos tornam-se perecíveis e voláteis, quando vistos pela ótica do fluxo de mercadorias. $\mathrm{Na}$ sociedade de consumo em que vivemos, o gosto pela novidade vai além da mera opção, transforma-se em dinâmica cultural, como já apontara Lipovetsky, em sua obra $O$ Império do Efêmero (1989). Nesse contexto, o “fantasma da inutilidade”, como define Sennett, se dissemina pelo mercado de trabalho, como um dos principais focos de tensão do indivíduo:

\footnotetext{
A fórmula segundo a qual a experiência vai perdendo valor à medida que aumenta tem uma realidade mais profunda na economia mais depurada dos dias de hoje. A extinção de capacitações é uma característica permanente do avanço tecnológico. A automação é indiferente à experiência. As forças do mercado continuam a fazer com que seja mais barato comprar novas capacitações do que pagar pelo retreinamento (Sennett, 2006: 94).
}

O mundo do trabalho incorpora o caráter da obsolescência da mão de obra, em situação similar à da transitoriedade do consumo, com a ressalva de que não são temporalidades equivalentes. A aceleração do consumo e sua mutabilidade tem como correspondente na esfera produtiva a flexibilização de procedimentos, a produção em plataforma, ou a partir de modelos pré-estabelecidos, que vão permitir pequenas mudanças que dão agilidade ao abastecimento do mercado com novidades, como no 
caso da indústria automobilística e do vestuário (que tem seu maior exemplo na marca Zara, de origem espanhola e dimensão global, representante da chamada fast fashion, com procedimentos padronizados capazes de lançar uma nova linha de roupas em cerca de três semanas).

Zygmunt Bauman, em sua obra Vida para consumo, marca a passagem da sociedade de produtores para a sociedade de consumidores, onde o imperativo do mercado, que determina a competição e a busca incessante pela sobrevivência das mercadorias ante a concorrência, passa à esfera humana, aos comportamentos e aos modos de parecer:

Para entrar na sociedade de consumidores e receber um visto de residência permanente, homens e mulheres devem atender às condições de elegibilidade definidas pelos padrões do mercado. Espera-se que se tornem disponíveis no mercado e que busquem, em competição com o restante dos membros, seu "valor de mercado" mais favorável. Ao explorarem o mercado à procura de bens de consumo (o propósito ostensivo de sua presença ali), são atraídos para as lojas pela perspectiva de encontrar ferramentas e matérias-primas que podem (e devem) usar para se fazerem "aptos a serem consumidos” - e, assim, valiosos para o mercado (Bauman, 2008: 82).

As práticas de consumo, no sentido da produção da subjetividade, delegada ao indivíduo que deve fazer escolhas, assumi-las e se lançar ao mercado como “desejável”, remete, indiretamente, à primeira noção de consumo de Marx: o consumo demandado pela produção, como aquisição de matérias-primas e uso de recursos para a transformação dos elementos da natureza em mercadorias por meio do trabalho, no panorama apontado por Bauman, transfere-se para o plano do indivíduo. Produzir a si mesmo para se tornar desejável, de acordo com as leis do mercado: consumir para se transformar em mercadoria consumível.

Como as duas esferas, do mundo do trabalho e da sociedade de consumidores, aproximam-se a partir de nosso objeto de pesquisa, as representações da esfera produtiva na narrativa publicitária? Uma vez que estamos situados na sociedade de consumidores, há uma generalização da lógica de “tornar consumíveis”, de mercadorizar todos os planos da atuação humana socialmente assimiláveis. No discurso publicitário, isso implica que a esfera produtiva se torna um lugar possível de tradução e de humanização, para servir de apelo ao consumo de produtos e marcas. Distante de 
filmes institucionais que apresentam as instalações das indústrias, as estruturas físicas das corporações, que não são fenômeno recente (pode-se afirmar que seu interesse nos dias de hoje está restrito ao mundo dos negócios, onde o efeito de racionalidade busca sobrepor-se à sedução, ao apelo sensorial), as versões publicitárias dos sistemas produtivos das mercadorias, do ambiente corporativo, dos aspectos materiais e imateriais que estão envolvidos tanto na indústria quanto no setor de serviços ganham autonomia de qualquer função referencial, para se ajustar às conotações do universo simbólico das marcas e sua mitologia. Essas conotações, geradas tanto pelo uso social do bem, quanto pelas narrativas publicitárias precedentes que lançam as mercadorias na economia de trocas simbólicas (Bourdieu, 2001: 25), a demarcar sua identidade como diferenciação da concorrência, são ponto de partida para o raciocínio criativo publicitário. Ou seja: a reconstrução dos processos de elaboração da mercadoria é determinada pelas significações do produto final, com todas as suas conotações e camadas estéticas. Os processos produtivos, sob essa ótica, tornam-se uma derivação lógica de como a mercadoria quer ser consumida, desejada pelo consumidor objetivado pela comunicação.

\section{Processos comunicacionais e a questão do ethos publicitário}

Como destacamos anteriormente, a comunicação publicitária é fundada na cultura de consumo contemporânea, interdependente de seu contexto mais amplo; concordamos com Baitello Junior (2005: 8), quando afirma que “comunicação e cultura constituem-se (...) em esferas indissociáveis.” Há um sentido de interação social que impede a leitura da publicidade como linguagem autônoma. Ressalta-se seu caráter dialógico: a publicidade é um dos melhores exemplos para a definição de retórica de Michel Meyer (1998: 26), que a conceitua como “a negociação da distância entre os sujeitos.” Essa negociação acontece através da linguagem. No caso da publicidade, objetiva-se a aproximação entre o anunciante ou a marca anunciada e o consumidor ao qual a comunicação se direciona; ao mesmo tempo, há uma estratégia de demarcação de alteridade, de diferenciação das significações da concorrência e dos não-consumidores, refletidos e refratados para construir o sentido de superioridade, de distinção, de superação da mercadoria anunciada ante aqueles que estão excluídos de seu universo simbólico. Como define Barthes (1975: 203), em seus estudos de Retórica: “O ethos é, 
no sentido próprio, uma conotação. O orador enuncia uma informação e, ao mesmo tempo, afirma: sou isso e não aquilo.”

Com Barthes, vemos os efeitos de sentido apreendidos dos enunciados como maneiras de dizer de um sujeito da enunciação, constituído em ator da enunciação através de uma totalidade de discursos enunciados, que transmitem uma personalização e uma corporalidade de si para o enunciatário da mensagem, ao comunicar algo. A questão do orador "ser isso e não aquilo", conforme se constitui discursivamente, aponta para o que consideramos a oposição fundamental do ethos: a relação entre identidade $x$ alteridade. Nesse espectro, o ethos pode ser definido por uma maneira de dizer que se constitui através de reiterações discursivas, que aponta para o recorte sóciocultural em que o enunciador delimita sua identidade, em relação a outros discursos em circulação em seu ambiente social.

Através da teoria de Maingueneau, vemos a modulação enunciativa como forma de conotar uma corporalidade que, juntamente com os traços psicológicos pressupostos pela maneira de dizer (apontados por Barthes), constituem o ethos no espectro teórico dos estudos da linguagem. A entonação que envolve a enunciação aponta para o foco de uma análise de seu processo constituinte, pressuposto pelos enunciados, que são a materialidade das estratégias de linguagem:

Parece-nos que a fé em um discurso, a possibilidade de que os sujeitos nele se reconheçam presume que ele esteja associado a uma certa voz (que preferiremos chamar de tom, à medida que seja possível falar do "tom” de um texto do mesmo modo que se fala de uma pessoa). (...) O tom está necessariamente associado a um caráter e a uma corporalidade (Maingueneau, 1997: 46-47).

De acordo com Bettetini, o corpo do enunciatário, fisicamente ausente na relação interacional da produção audiovisual, reconstitui-se em simulacro, através da mensagem, na interação simbólica com o enunciador projetado pela comunicação. Esse simulacro do enunciatário se ajusta a uma prótese simbólica:

Una prótesis que no sustituye órganos ausentes y que no extiende fisicamente el radio de acción de cualquier órgano, sino que "finge" el funcionamento receptivo de órganos presentes y no estimulados y que, por este motivo, vuelve a entrar por derecho en el orden de lo simbólico (Bettetini 1996: 36). 
A proposta de mediação entre enunciador e enunciatário através da mensagem publicitária, vista sob a abordagem de Bettetini, acompanha a idéia do marketing da completude: as mercadorias, ao se apresentarem como resoluções para ausências, como “estimuladores de sentidos”, como ativadores de sensações, sentimentos e ações (projetados como simulacros), podem gerar afetações por parte do consumidor, nesse processo de consumo simbólico que se baseia na identificação com a corporalidade e com o caráter expressos pela mensagem que lhe é destinada. Discutimos a seguir, através dos filmes analisados, de que maneira as significações da esfera produtiva servem a esse projeto de identificação da publicidade com seus consumidores.

\section{Análise dos filmes publicitários}

\subsection{Representações do processo produtivo como tradição - Bauducco - "Segredo"3 (2008) (30 segundos)}

A marca Bauducco tem origem brasileira, conhecida principalmente pela produção de panettones, receita tradicional italiana. Trata-se de uma empresa que se inicia de maneira artesanal com a chegada da família Bauducco ao Brasil, vinda da Itália. Após a abertura de loja própria de doces, em São Paulo (em 1952), em dez anos o Sr. Bauducco, patriarca da família, inaugura sua primeira fábrica. Segundo dados da própria empresa, atualmente é a maior produtora de panettones do mundo, com quatro fábricas instaladas no Brasil ${ }^{4}$. Evidentemente, o aspecto artesanal ficou em sua origem, como mito fundador, mas persiste como releitura simbólica por meio da linguagem publicitária.

No filme "Segredo", um homem, de meia idade e aparência simpática, cuida de maneira artesanal da produção dos biscoitos da marca. O filme alterna a imagem desse homem com tomadas em close, onde aparecem suas mãos em primeiro plano, manipulando os ingredientes, como a massa, mel, banana, canela, chocolate, de forma lenta, cadenciada. Os ingredientes ganham uma dimensão mítica, profunda, tal qual Barthes identificou na propaganda de Omo, especificamente na imagem da espuma, em uma imagem simultaneamente "profunda e aérea": "a espuma pode mesmo ser o signo de uma certa espiritualidade” (Barthes, 1987: 30). Há uma introspecção que se

\footnotetext{
${ }^{3}$ Comercial disponível no site YouTube no endereço: http://www.youtube.com/watch?v=FUxT083Yokg , acesso em 13/3/09.

${ }^{4}$ Informações obtidas no site da empresa: www.bauducco.com.br, acesso em 8 de março de 2009.
} 
transmite pela ação, pela maneira densa, calma com que as receitas são preparadas, e pela montagem que potencializa esses significados ao unir o efeito slow (redução da velocidade) com um movimento que se complementa na sucessão de cortes, de forma harmônica. A trilha orquestral, em tom emotivo e ascendente, atribui um valor transcendente a esse trabalho. No final, a câmera se aproxima do homem que, com seu sotaque italiano, dirige-se diretamente à câmera, para o observador projetado pela composição audiovisual: “Vocês pensam que o segredo tá aqui, né?”, mostrando suas mãos, até então o signo privilegiado na composição interna da mensagem. Ele continua, em tom sussurrado, levando a mão direita ao lado esquerdo do peito, onde simbolicamente se situa o coração: “No, tá aqui”. No encerramento, o pack shot, ou o plano de demonstração do produto, no caso, da linha de biscoitos da marca, entra o narrador em off: "Da família Bauducco para a sua família”. O ethos emotivo de Bauducco, composto pela narrativa audiovisual de sua publicidade, sustenta as significações de seu sistema produtivo, como a grande indústria movida pelo coração de um homem. A imagem representada de seu idealizador ressemantiza a operação fabril e a estrutura corporativa direcionada a milhões de consumidores em um diálogo simulado entre famílias: a família Bauducco e a do consumidor que se projeta na mensagem. A marca se coloca como provedora de mercadorias que pretendem ser reconhecidas como gestos de afeto, como operadores totêmicos que recuperam os vínculos emocionais mais estreitos. O trabalho afetivo se sobressai.

\subsection{A memória afetiva como produtora da mercadoria - Mitsubishi L200 Triton - “Carro dos sonhos”" (2008) (1 minuto)}

A Mitsubishi, corporação que engloba mais de 40 empresas independentes, com origem em Osaka, Japão, deu início à produção de automóveis em 1917. O significado de seu nome está expresso pelo seu logotipo: "três diamantes". O mito de sua origem é construído em torno de seu idealizador, Yatora Ywasaki, que fundou uma companhia de navegação no século XIX, com "3 velhos barcos a vapor, que estiveram na origem do logo Mitsubishi”6 . Ao longo de sua história, a montadora ficou conhecida, entre outros,

\footnotetext{
${ }^{5}$ Comercial disponível no site YouTube no endereço: http://www.youtube.com/watch?v=tA8BxwAZG_g\&NR=1 , acesso em 13/3/09.

${ }^{6}$ Fonte: site http://www.mitsubishimotors.com.br/main.cfm/site/2/content/1, acesso em 13 de março de 2009.
} 
pelos seus automóveis de tração 4x4, apropriados para terrenos irregulares. Essa linha de automóveis, as chamadas picapes off road, tem ganhado versões para uso no espaço urbano, que dá destaque em seus apelos de venda ao conforto e ao design. É o caso do Mitsubishi L200 Triton.

O comercial se inicia com a imagem escura, em seguida atravessada por facho de luz que revela uma mão masculina esticando-se pelo vão do tijolo tirado de uma parede para pegar uma caixinha empoeirada. Uma sequência com predominância de closes e ritmo cadenciado mostra a caixinha sendo puxada cuidadosamente através do buraco na parede - uma caixa antiga, esquecida no tempo por um menino que agora, já adulto, de meia-idade e cabelos grisalhos, vai buscá-la em seu esconderijo e em sua memória. Com cuidado, tira o pó de sua superfície, abre a tampa e encontra, entre outras pequenas coisas, um carrinho de brinquedo, um modelo de passeio, na cor prata. Em tom delicado, edifica-se o ethos expresso pela comunicação: uma música que lembra uma canção de ninar, leve e circular, embala as imagens do homem que aproxima o carrinho de sua face e olha-o fixamente, com ternura, como se revivesse sua experiência passada com o brinquedo. Walter Benjamin, em texto sobre brinquedos e jogos infantis, lança a questão: “mas quando um poeta moderno diz que para cada um existe uma imagem em cuja contemplação o mundo inteiro submerge, para quantas pessoas essa imagem não se levanta de uma velha caixa de brinquedos?” (Benjamin, 2002: 102). O comercial guarda esse sentido de memória afetiva, de idealização da infância como momento sublime de formação do adulto e do brinquedo como conector dessa temporalidade. A música intensifica seu tom emotivo ao acompanhar os passos lentos de outro homem, um pouco mais jovem, visto ao fundo, quando ao primeiro plano vemos uma estante com outro carrinho infantil entre livros, agora uma escavadeira vermelha. Um plano de conjunto mostra o personagem em uma sala ampla a pegar o brinquedo na estante, com delicadeza. A câmera se aproxima, lentamente, envolvendo com uma atmosfera de tensão emotiva, quase transbordante, a ação do homem a recuperar o menino de outrora. Os carrinhos são desencadeadores das significações de passado, da memória pessoal. Um terceiro homem encontra seu brinquedo em uma gaveta; todos os três, em uma faixa etária entre 30 e 50 anos, estão sozinhos nos ambientes de seus lares, experimentando uma viagem particular ao passado, afastados momentaneamente dos laços humanos que o identificam no presente. Esse terceiro 
homem, ao sustentar o brinquedo com as duas mãos, olha com ternura para frente, como se mirasse o passado e as memórias dele derivadas.

Um segundo momento do comercial se inicia com o close de uma mão masculina que posiciona um carrinho prata em uma calçada, o mesmo carrinho que aparece nas primeiras cenas. A música cresce com o som de um acordeón que dá um tom mais melancólico, mais intensamente emotivo ao comercial, e também mais adulto. A câmera se afasta, vemos o primeiro homem a aparecer no comercial com um dos joelhos no chão, posicionando o carrinho em amplo espaço a céu aberto, um calçadão no centro de São Paulo, mais exatamente no Pátio do Colégio, marco zero de origem da grande metrópole, a partir da missa celebrada ali em 25 de janeiro de 1554 pelos padres da Companhia de Jesus. Este lugar, marco histórico fundador, torna-se emblemático em sua intersecção com os aspectos memorialísticos do comercial. História da cidade e memória infantil se entrecruzam para produzir a reiteração das significações de passado refletido e refratado pelo comercial, projetado no universo simbólico da marca anunciada.

Vemos então uma sucessão de homens, alguns meninos e mulheres, vindos de todos os lados, em direção a esse lugar onde os carrinhos são empilhados. Os cortes são rápidos, a montagem produz um sentido de harmonia na passagem entre os planos. Os brinquedos compõem montes que, vistos na sucessão de closes e planos próximos, mostram tanto as ações de colocar os brinquedos nas pilhas quanto a circulação das pessoas, sugerindo uma multidão que se une pelo mesmo impulso. Na sequência, a câmera mostra detalhes do que seria a picape Mitsubishi L200 Triton, em tamanho natural, composta pelos carrinhos de brinquedo. No momento em que o narrador em off diz: "Imagine tudo que você sempre sonhou de um carro, agora numa cabine dupla. Chegou o Mitsubishi L200 Triton. O 4x4 que você sempre sonhou”, a música incorpora um tom orquestral, que alça a novo patamar a emotividade do comercial. A partir de um mesmo plano de conjunto, intercalado pela imagem de homens admirando o automóvel, acontece a transformação do Mitsubishi, que passa da composição por carrinhos a uma estética comum, de como é encontrado nas lojas. A câmera posicionada na parte interna revela o painel do carro e, ao fundo, os olhares curiosos daqueles que ajudaram a construir o Mitsubishi com seus carrinhos de brinquedo. Uma tomada geral em plongée mostra toda a multidão que se aglomera em torno da picape, a admirá-la, sucedida pelo 
plano final, com a inscrição “4x4 é Mitsubishi”, em que o logotipo da marca substitui a letra x, situando-se como sinônimo dessa característica técnica.

De acordo com as conotações do comercial, o resultado do sistema produtivo de Mitsubishi é a memória pessoal, a transformação dos sonhos em mercadoria. Os meninos que projetaram seus sonhos a partir de um carrinho de brinquedo são o motor da concepção e da produção da picape, que se apresentam como síntese desse imaginário múltiplo, das mais variadas cores e modelos, de homens de variados estilos e idades. O sentido da memória é ao mesmo tempo pessoal, em suas nuances próprias, e também coletivo, por ser derivado de comportamentos comuns a várias gerações anteriores ao advento e à disseminação dos jogos eletrônicos entre as crianças. O trabalho artesanal é significado como manifestação do desejo de pessoas que tomam a iniciativa de serem produtores de seu sonho de consumo, em uma alegoria da sociedade de consumo e do consumidor como sujeito ativo na concepção das ofertas do mercado contemporâneo. Dessa maneira, Mitsubishi constrói o imaginário de seus processos produtivos a partir de um sentido compartilhado com os seus possíveis consumidores, como decorrência de histórias e sonhos pessoais que convergem para uma mesma mercadoria. O ethos delicado e emotivo do comercial é o revestimento audiovisual dessa materialização do sonho em imagem midiática.

\subsection{A história social editada pela marca - Johnnie Walker - "Striding man”7 (2008) (30 segundos)}

O comercial "Striding man” (andarilho) foi concebido em Londres e veiculado globalmente para divulgar a marca centenária de uísque Johnnie Walker. “Stride”, palavra inglesa, significa, entre outras coisas, “atravessar algo a passos largos”; esse campo semântico ordena toda a linha de comunicação da marca, sintetizada pelo conceito de progresso, como ação humana que objetiva romper barreiras e desafios. $\mathrm{O}$ slogan atual de Johnnie Walker, “keep walking” (continue andando), foi lançado em 1999. A marca tem seu mito fundador situado no século XIX, na figura de John Walker, herdeiro de um pequeno comércio deixado por seu pai; foi ele quem incluiu a produção artesanal de uísque no negócio, que era vendida diretamente aos clientes da loja. O

\footnotetext{
${ }^{7}$ Comercial disponível no site YouTube no endereço: http://www.youtube.com/watch?v=ORy-scrGk0Y , acesso em 13/3/09.
} 
famoso logotipo da marca teve sua primeira versão em 1909, composto pela imagem de um homem, vestido elegantemente, preservado no movimento de caminhada a passos largos. Segundo o site da marca, foi encomendado em homenagem a John Walker pelos seus netos, então proprietários da empresa ${ }^{8}$.

O comercial localiza a história de seu fundador como marco inicial de acontecimentos históricos da humanidade, que são alinhados cronologicamente como expressões do conceito "keep walking”. O filme tem fotografia em preto e branco, reforçando as significações de narrativa histórica, de volta ao passado. Os acordes iniciais da trilha sonora orquestral acompanham a abertura súbita dos portões de madeira de um galpão. Um barril de madeira rompe caminho. O plano seguinte é um travelling em plano de detalhe, mostrando botas de couro que vestem um homem de passos decididos. O plano de conjunto a seguir apresenta o homem, com bota, colete sobre camisa, compondo um vestuário de épocas passadas, empurrando o barril que, visto lateralmente, mostra o logotipo atual da marca Johnnie Walker. Na legenda, lê-se: “1840 - Johnnie Walker a um passo do mundo”. Esse movimento de caminhar adiante a passos largos, apresentado pela visão lateral dos personagens caminhando da esquerda para a direita da tela, constrói um sentido de continuidade, na passagem de um marco a outro, dessa "evolução" que tem início nos primeiros passos do fundador da marca de bebidas. Na próxima sequência, um operário de construção civil caminha em uma estrutura metálica em um prédio em construção, enquanto empurra uma viga, com a paisagem ao fundo, revelando tratar-se de um arranha-céu. A legenda remete à construção do Empire State Building, que ficou registrada para a posteridade através de fotografias emblemáticas desse período do capitalismo moderno: "1930 - o homem a um passo da construção de Nova Iorque”. A música dá um tom dramático, épico às cenas: o ritmo é repetitivo, frenético, em tensão crescente. O passo seguinte leva à década de 1960, a um protesto de homens negros, vestidos com paletós, que caminham e se confrontam com a repressão policial, carregando placas com palavras de ordem. Em primeiro plano, um homem visto somente da cintura para baixo, destacando seus passos decididos. A locução em off ancora os significados na luta contra o racismo: “1964 - o homem a um passo da igualdade”. A seguir, um astronauta no espaço, em progressão lenta, com a lua ao fundo, e a legenda: "1969 - o homem a um passo do

\footnotetext{
${ }^{8}$ Informações obtidas no site http://www.johnniewalker.com.br, em 13 de março de 2009.
} 
infinito”. Em seguida, jovens caminham com seus tênis sobre os escombros do muro de Berlim. Um deles ergue um martelo, com expressão vitoriosa. Um grupo sustenta um tronco de madeira e se projeta contra o muro. A legenda ancora os significados da imagem: “1989 - o homem a um passo de unificar a Alemanha”. Flashes de máquinas fotográficas recuperam a memória de um momento histórico amplamente documentado com imagens, um evento predominantemente midiático. A sequência final do comercial é uma tomada em travelling e plano de conjunto de um homem vestido elegantemente com paletó e sapatos, caminhando de maneira decidida entre árvores. A legenda, agora, sobrepõe-se à imagem: “Quem sabe aonde um passo pode te levar?” A imagem desse homem se transforma no logotipo da marca Johnnie Walker, na cor amarela sobre fundo preto. O narrador em off, uma voz masculina, encorpada, fala o slogan e a marca, enquanto os mesmos surgem no plano final: “Keep walking. Johnnie Walker”.

Em movimento circular, a “evolução” de Johnnie Walker tem início e se encerra em seu universo. Entre um extremo e outro, organizam-se acontecimentos históricos, sintetizados e conectados pelo "passo" que cada um representa, equiparados ao feito do fundador da indústria de uísque - o que nos remete ao mundo do trabalho como lugar transcendente, com características do espírito protestante estudado por Max Weber. História social e memória corporativa confundem-se, entrelaçam-se: a marca propõe ser reconhecida como o espírito desencadeador de transformações importantes na história social do homem. Ao mesmo tempo, sugere, implicitamente, que o consumidor, ao se apropriar de seu universo simbólico, transfere para as pequenas vitórias e superações da esfera pessoal a dimensão mítica dos grandes feitos, oferecendo como exemplo máximo o trabalho de seu fundador. Assim, o ethos épico e revolucionário de Johnnie Walker defende seu lugar na história e na vida cotidiana.

\section{Considerações finais}

As estratégias audiovisuais publicitárias analisadas neste estudo, que incorporam significações da memória e da história, utilizam como base o tom épico, o apelo ao ethos emotivo, à narrativa mítica. Na referência ao mundo do trabalho, os sentidos da atividade artesanal são utilizados para destacar o fator humano como determinante do universo simbólico mobilizado pela comunicação, incluindo tanto o produtor quanto o consumidor - este, alçado ao papel de colaborador na construção desse imaginário. O 
processo publicitário serve como camada estética da mercadoria, como óculos sociais que traduzem a impessoalidade dos conglomerados industriais e seus processos automatizados em trabalho imaterial, em produção afetiva, através de uma referencialidade própria, da ancoragem no mito, na dimensão lúdica, onírica. Dessa forma, a publicidade assume o papel de produção simbólica, que se situa no último estágio dos sistemas produtivos a que serve - como promotor da mercadoria no plano do imaginário social e como processo de esvaziamento, de sublimação dos paradoxos do mundo do trabalho. Assim, refletida e refratada pela linguagem publicitária, a transformação do trabalho em mercadoria ganha novas dimensões quando consumida no plano simbólico das marcas.

\section{Referências bibliográficas}

BAITELLO JUNIOR, N. A era da iconofagia: ensaios de comunicação e cultura. São Paulo: Hacker, 2005.

BARTHES, R. Retórica antiga. In: COHEN, J. [et alii]. Pesquisas de retórica. Petrópolis: Vozes, 1975.

BARTHES, R. Mitologias. São Paulo: Difel, 1987.

BAUMAN, Z. Vida para consumo: a transformação das pessoas em mercadoria. Rio de Janeiro: Jorge Zahar, 2008.

BENJAMIN, W. "Brinquedos e jogos: observações marginais sobre uma obra monumental”. In: __ Reflexões sobre a criança, o brinquedo e a educação. São Paulo: Duas Cidades / Ed. 34, 2002, pp. 95-102.

BETTETINI, G. La conversacion audiovisual. Madrid: Cátedra, 1996.

BLIKSTEIN, I. Kaspar Hauser ou a fabricação da realidade. São Paulo: Cultrix, 1985.

BOURDIEU, P. A economia das trocas simbólicas. São Paulo: Perspectiva, 2001.

GEERTZ, C. A interpretação das culturas. Rio de Janeiro: Zahar, 1978.

HARDT, M.; NEGRI, A. Império. Rio de Janeiro: Record, 2006.

HARVEY, D. Condição pós-moderna. São Paulo: Loyola, 2001.

HAUG, Wolfgang F. Crítica da estética da mercadoria. São Paulo: Unesp, 1997.

LIPOVETSKY, G. O império do efêmero. São Paulo: Cia. das Letras, 1989.

MAINGUENEAU, D. Novas tendências em análise do discurso. Campinas: Pontes / Unicamp, 1997.

MARX, K. Trabalho estranhado e propriedade privada. In: ANTUNES, R. (Org.). A dialética do trabalho: escritos de Marx e Engels. São Paulo: Expressão Popular, 2004, pp.173-195. 